\title{
Vision paper
}

\section{How to achieve resource use efficiency in} integrated food and biobased value chains?

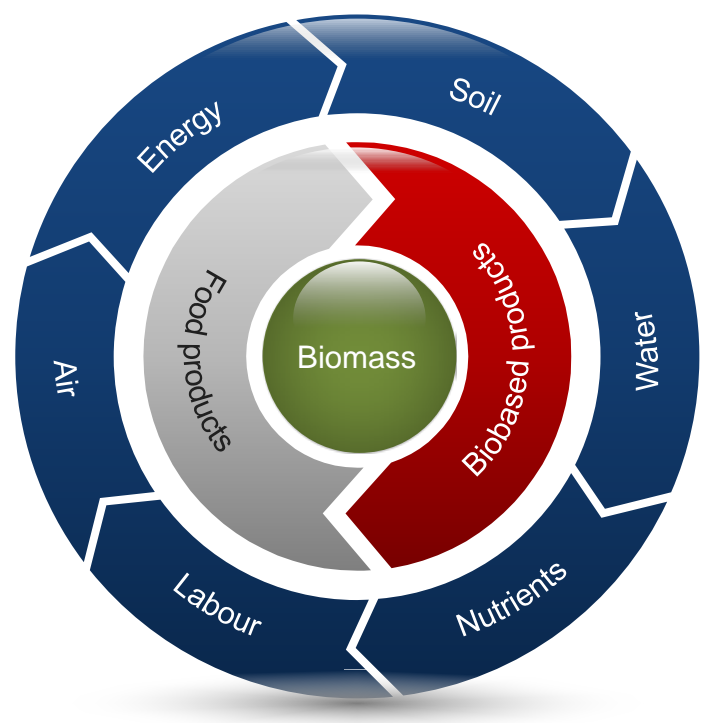

E. Annevelink (ed.), B. van Gogh (ed.), P. Bartels, J. Broeze, J. van Dam, J. Groot, N. Koenderink, M. van den Oever, J. Snels, J. Top and D. Willems

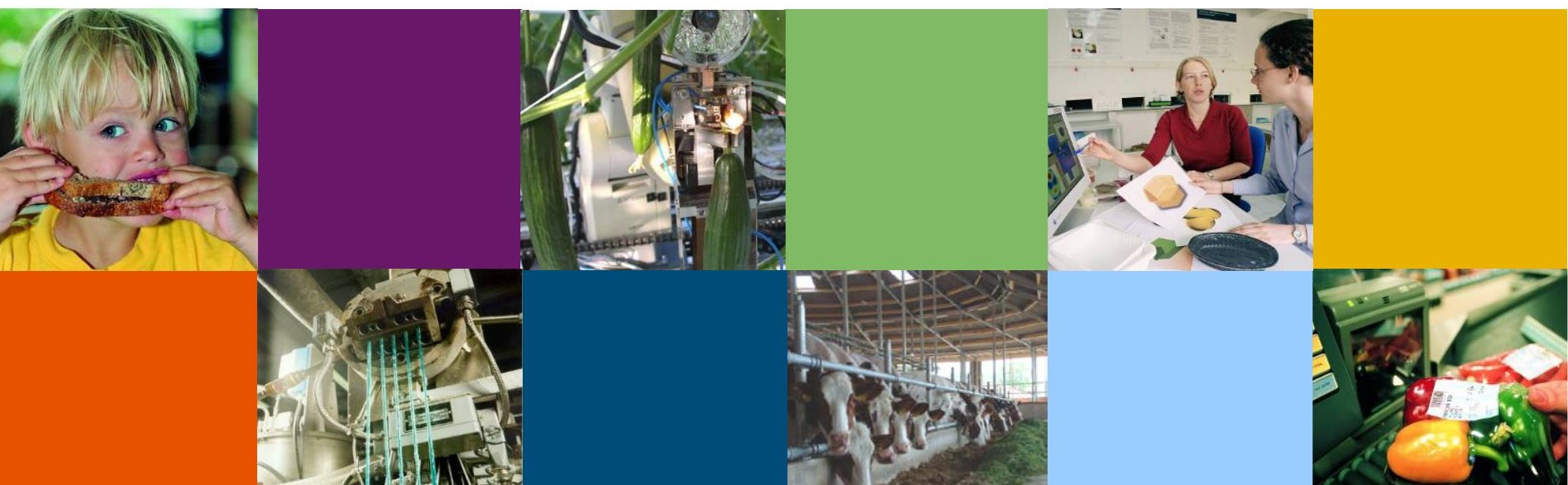




\section{Colofon}

Title

Author(s)

Number

ISBN-number

DOI-number

Date of publication

Version

Confidentiality

OPD-code

Approved by

Review

Name reviewer

Sponsor

Client
How to achieve resource use efficiency in integrated food and biobased value chains? dr.ir. E. Annevelink (ed.), ir. J.B. van Gogh (ed.), dr.ir. P.V. Bartels, dr.ir. J. Broeze, dr. J.E.G. van Dam, ir. J.J. Groot, dr. N.J.J.P. Koenderink, ir. M.J.A. van den Oever, drs. ing. J.C.M.A. Snels, prof.dr.ir. J.L. Top, dr. D.J.M. Willems 1720

978-94-6343-116-3

http://dx.doi.org/10.18174/407896

2 February 2017

Final

no

6234104200

Dr. N.J.J.P. Koenderink

Intern

Dr.ir. H.C. Langelaan

TKI Agri \& Food

Ministerie van Economische Zaken

Wageningen Food \& Biobased Research

P.O. Box 17

NL-6700 AA Wageningen

Tel: +31 (0)317480084

E-mail: info.fbr@wur.nl

Internet: www.wur.nl/foodandbiobased-research

(C) Wageningen Food \& Biobased Research, institute within the legal entity Stichting Wageningen Research All rights reserved. No part of this publication may be reproduced, stored in a retrieval system of any nature, or transmitted, in any form or by any means, electronic, mechanical, photocopying, recording or otherwise, without the prior permission of the publisher. The publisher does not accept any liability for inaccuracies in this report. 


\section{Contents}

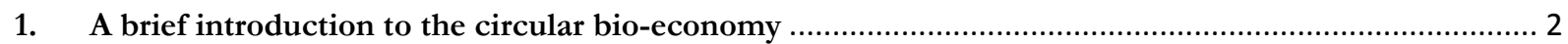

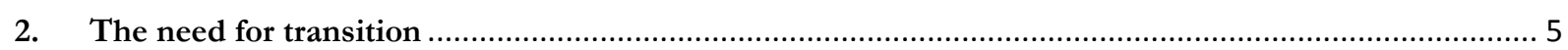

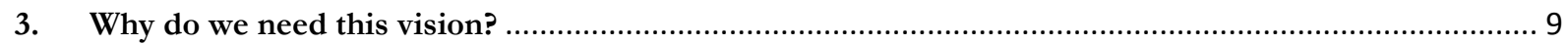

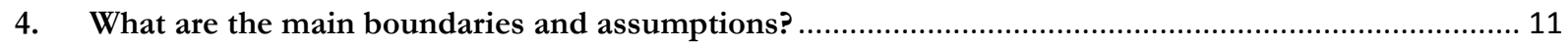

5. Vision statement: integrated adaptive value chain networks needed in the bio-economy .................. 13

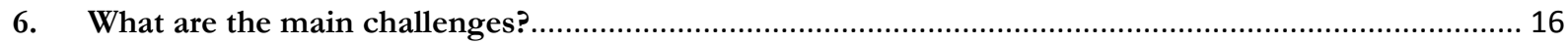

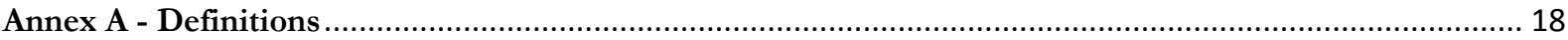

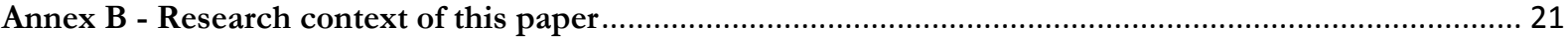

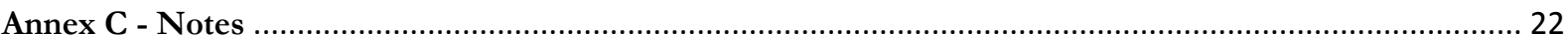




\section{A BRIEF INTRODUCTION TO THE CIRCULAR BIO-ECONOMY}

Purpose of this vision paper
This publication contains a vision, formulated by research experts in food and biobased production, on how to achieve increased efficient and effective use of available resources during the production and (re)processing of biomass for food and biobased products, feed and energy. This paper briefly elaborates on the transition to a sustainable bio-economy (see graph 1), focusing on the needs and requirements from a value chain perspective. A growing number of representatives from scientific, governmental, political, business and societal organisations consider the transition from a fossil fuelled economy to a bioeconomy as a 'conditio sine qua non' for a competitive low-carbon growth model. Using renewable resources is essential for increasing the sustainability of the bio-economy and for the mitigation of global warming. The urgency of this transition was recently expressed at the European Bio-economy Stakeholder Conference in Utrecht. Stakeholders from large and small companies, NGOs, associations and national and regional governments from 30 European countries phrased this in their concluding 'Manifesto':

\section{"We regard the transition to a sustainable and circular bio- economy as inevitable"."1)}

By expressing this vision on how to achieve resource use efficiency in integrated food and biobased value chains, Wageningen Food \& Biobased Research wants to engage into a constructive debate with stakeholders from the private and public sector that all have an interest in increasing the sustainability of the bio-economy. One of the objectives of this debate will be to assess how scientific research can support and contribute to the transition process to achieve a more efficient and effective use of the available resources.

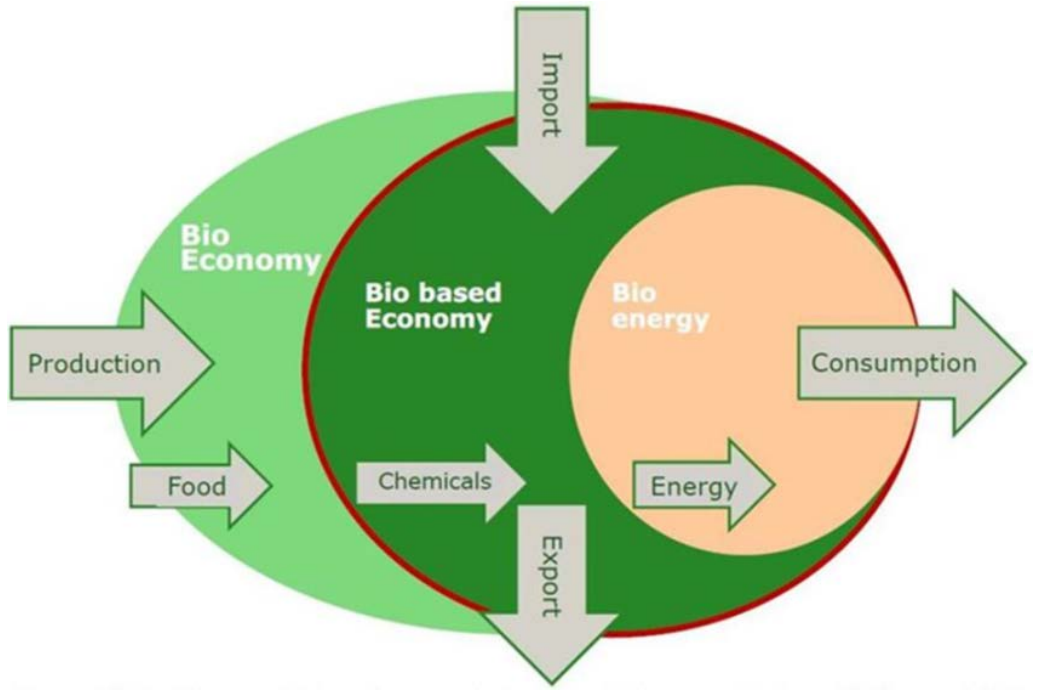

Graph 1. Schematic representation of the bio-economy, including the biobased economy. 
Efficiency and effectiveness

With this vision paper the authors intend to make a first step on the road of applying a systems approach to shape the circularity of biomass value chains (to achieve a sustainable bio-economy). They argue that by carefully addressing integration and circularity in biomass value chains, a more efficient use of available resources ('doing things right') will be enabled.

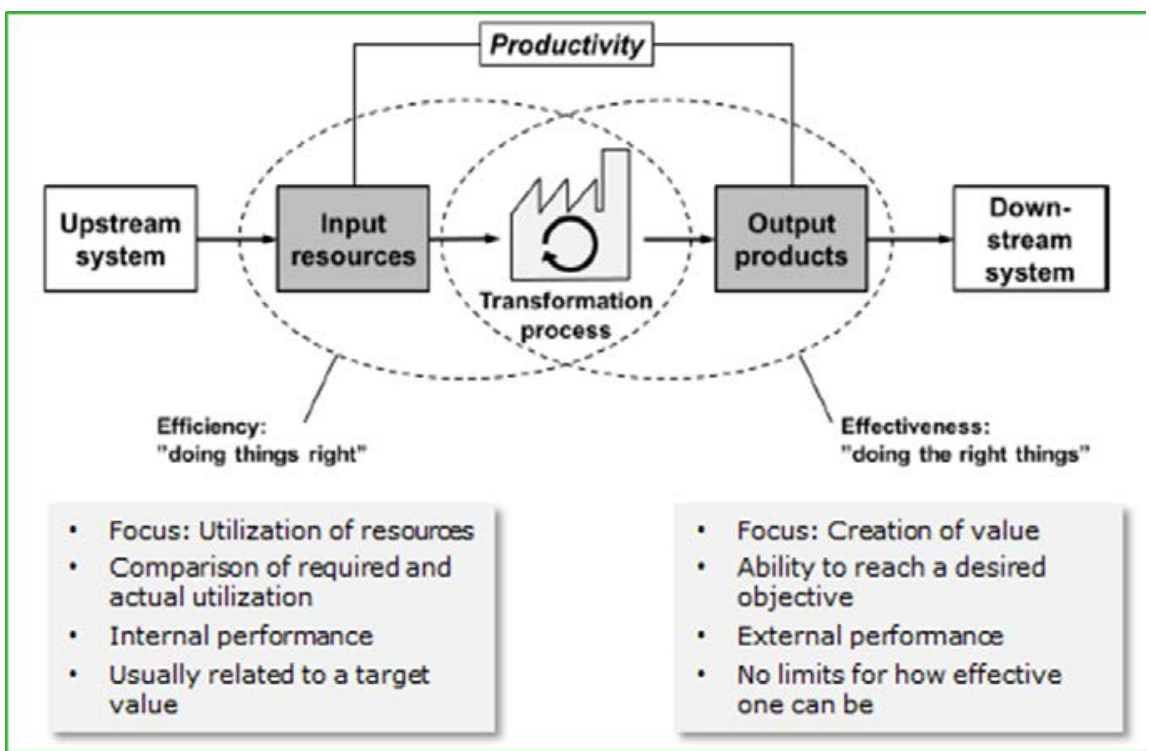

Graph 2. Efficiency and effectiveness in the value chain (Lieder 2014).

The authors want to follow up on the objectives and challenges that have been formulated in several (political) agendas on realising the circular economy. ${ }^{2}$ The MacArthur Foundation refers to this as 'reinventing a regenerative food system'. Circularity of the bio-economy does not necessarily result in the effective use of resources ('doing the right things'). The effectiveness of the resources used in the production and processing of biomass into food and nonfood products is first of all subjected to the principles of using the biomass. Stakeholders will need to agree upon these principles. The EU Standing Committee of Agricultural Research (SCAR), a European advisory body on research policies for the EU member states and the European Commission, has recently published their $4^{\text {th }}$ Foresight report, in which such a set of principles are defined (see section 3).

Structure of this paper
Besides this introduction section the paper includes six sections. The need for a transition to a sustainable bio-economy is described in section 2. This sections also briefly deals with the challenges and preconditions for value chains to enable such a transition. Section 3 contains a description of the boundaries and assumptions that are relevant for the vision. This is followed by the objective of this vision paper (section 4). Section 5 then contains the vision statement, followed by the formulation of a number of economical, logistical, technical 
and legal challenges (section 7). Where deemed appropriate definitions of specific terms used in this paper are explained in Annex A of this paper. The annex also contains an explanation of the research context of this vision paper (Annex B). Finally annex C contains notes and references to literature. 


\section{THE NEED FOR TRANSITION}

Challenges for The agri \& food sector is on the brink of a fundamental change due to a series of the agri \& food sector global developments: ${ }^{3,4)}$

- Ecological developments: climate change, loss of biodiversity, depletion of fossil resources, growing scarcity and degrading quality of natural resources.

- Demographic developments: growing world population, urbanisation, migration flows.

- Economic developments: increase of income, volatility of food prices, growing e-commerce.

- Social-cultural developments: growing awareness of link between nutrition and health, social innovation (social entrepreneurship), digitalisation.

These global developments have an effect on the availability and use of the world's natural resources and raw materials. In the near future we face a growing demand for biomass (feedstock of biological origin) for the production of food, feed, chemicals, materials and energy. This will require a sustainable management of these resources. Substitution of fossil sources by renewable resources will reduce our dependency on non-renewable resources. After all, fossil sources of chemicals, materials, fuels and energy are finite. Furthermore, the associated greenhouse-gas emissions are increasingly posing climate problems.

Transition to a The need for a sustainable use of resources requires a transition from an sustainable circular bioeconomy economy based on fossil resources to a sustainable bio-economy. In such a bioeconomy, biomass is the key renewable resource not only for food and feed supply, but also for the production of biobased materials, chemicals and energy (see Graph 3). So the biobased economy is included as a part of the wider bioeconomy. The bio-economy provides alternatives to fossil-based products and energy, and contributes to a low-carbon circular bio-economy. ${ }^{5)}$ In the circular bioeconomy waste does not exist, consumables are returned to the biosphere without negative effects after a sequence of bio-cascading steps, contributing to its restoration, and renewable energy is used to fuel the processes. ${ }^{\text {) }}$ 


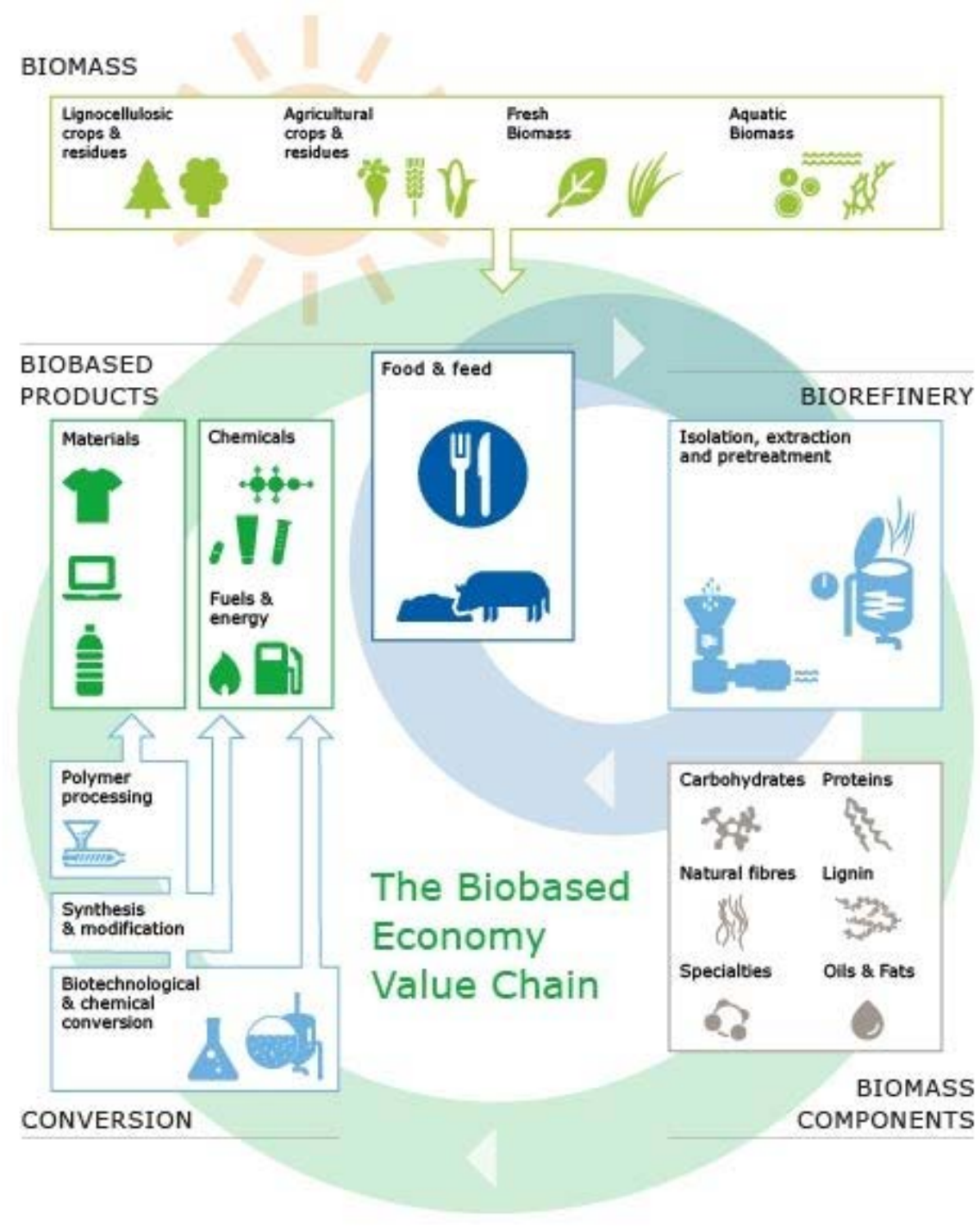

(CWageningen Food \& Biobased Research, 2016

Graph 3. Valorisation of biomass in the circular biobased economy.

Biomass cascading
The transition towards a sustainable bio-economy poses challenges for the system of production and consumption of goods. Industry will have to find solutions for the growing demand for biomass as feedstock for both food, feed and biobased products. Various biomass value chains will increasingly be intertwined because different industrial producers will need the same biomass resources for their production. Increasing the resource use efficiency during production and consumption (decreasing food waste) is therefore an important precondition for achieving a sustainable bio-economy. Cascading of biomass will increase the resource use efficiency and it will also generate more added value (Graph 4). Therefore, biomass cascading is an important part of the solution to obtain circularity in the bio-economy. ${ }^{7)}$ 


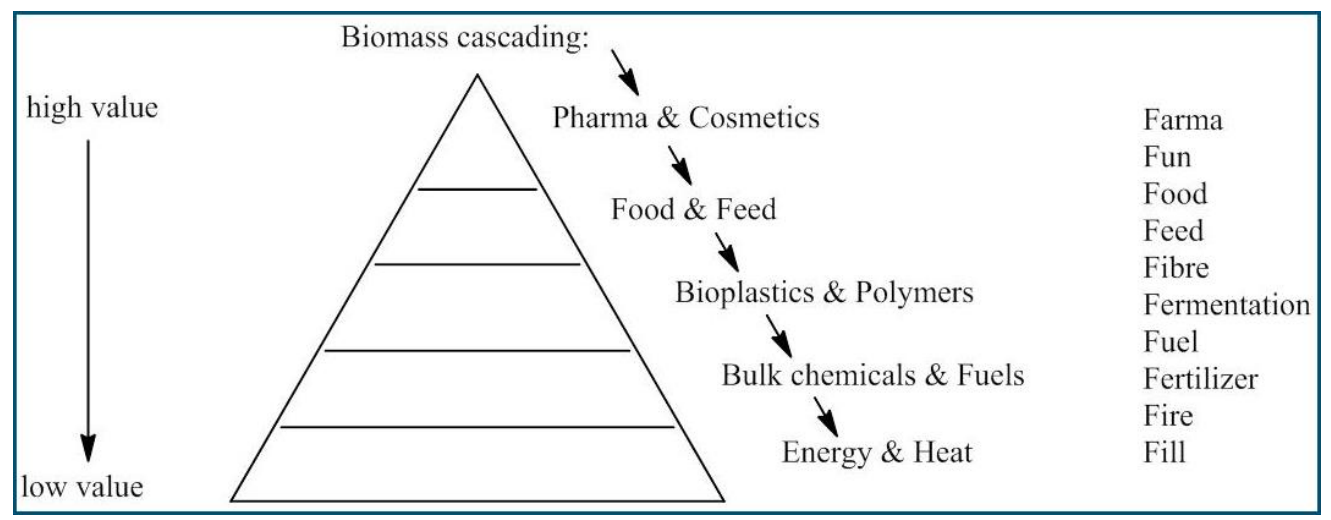

Graph 4. Biocascading pyramid.

Four principles for the use of biomass
Experts from the Standing Committee of Agricultural Research (SCAR) formulated the bio-economy as the way to deliver on the European goals of food security and sustainable resource management. It should reduce our dependency on non-renewable resources, tackle the climate change problem, create new jobs and maintain the competitiveness of the European economy. SCAR formulated four principles for the use of biomass that must be abided by to achieve a sustainable bio-economy in Europe:

- Food first: availability, affordability, access and utilisation of nutritious and healthy food.

- Sustainable yields: taking into consideration the renewable nature of biomass production and application of economic rules that govern the exploitation of renewable resources.

- Cascading approach: the concept of cascading prescribes that biomass is used sequentially as effectively possible, first as material (for food and feed, for pharmaceutical or chemicals products, and for materials), and finally for energy. Scientific research and technological development can extend the possibilities to extract potentially new functionalities from biomass, and so alter cascading options and sequencing in correlation with the value of these functionalities.

- Circularity: waste is traditionally generated where the costs of reuse and recycling are higher than the value that could be created. However, in the circular economy waste does not exist anymore as all materials are valued as "input resource" (Graph 2).

What is needed For the transition towards the bio-economy, the development of knowledge and for the transition? technologies for the implementation of innovations (e.g. the biorefinery concept) is not enough. The integration of different types of value chains and regimes is also a precondition for a transition. This requires a successful utilization of entire crops, the valorisation of by-products and recycling residual biomass streams in accordance with the cascading steps. Transition is therefore not just a process of 
technical innovation but it also requires a broad systems approach, in which the whole system of interconnected biomass value chains and their environment is taken into account in. In this systems-approach the afore-mentioned set of four principles guides the efficient and effective processing of biomass feedstocks. This vision paper provides the conceptual framework for creating insight in the landscape of connected biomass value chains in the circular bio-economy. 


\section{WHY DO WE NEED THIS VISION?}

What is the objective of this vision paper?

Timeframe

Ontology development
Value chains, in which bioresources are processed into intermediates for food and biobased purposes, are interdependent when it comes to the availability of sufficient good quality feedstock. Push and pull strategies in other industries to make their products in a more environmentally sustainable way, such as in the chemical industry and in the civil engineering and energy sector, have an effect on the share of products from these industries that is produced from renewable feedstocks (biomass). Innovations in technology and product engineering will enable cross-overs between traditionally biomass-based value chains, and chains that are based on finite fossil resources. The bio-economy, in other words, offers opportunities for synergy between sectors or industries in terms of valorisation of biomass, but it also poses threats in terms of inefficiency and ineffectiveness of the resources used in individual value chains. The resilience of the bio-economy will therefore depend on the ability to maximise the resource efficiency and effectiveness of these value chains as a flexible network. Circularity of biomass flows and the cascading of residue streams will secure the maximised efficiency of resources used.

This vision serves as a starting point for developing concepts, methods and tools that support designing (new) value chains in the circular bio-economy while enhancing the resource use efficiency and effectiveness. The underlying general question is how to find ways to enable actors in these value chains to assess the impact of their activities and decisions on the use of bioresources in their processes. The vision should be input for further research on a broad systems-approach that can support, guide and optimise a network of both food and biobased value chains in the near future. ${ }^{8,9)}$

The timeframe for this vision paper is set at the year 2030. We have opted for this period as it coincides with other relevant (political) agenda's, such as the UN Agenda for Sustainable Development and the Circular Economy Package of the European Commission. For the year 2030 it is expected that the global demand for energy and resources will have nearly doubled in comparison with the year 1990. This would largely be the result of the growing number of middle class consumers in emerging countries. Also for advocates of the circular economy such as the MacArthur Foundation, the year 2030 forms a target for transition towards circular systems. The timeline towards 2027 in the research agenda's for TKI Biobased Economy (TKI BBE) is also relevant to mention in this case.

Implementing this vision requires a common language. Through the joint effort of researchers from a different background of respectively the food and 
biobased domain it will possible to develop an ontology (shared vocabulary) that reflects the different domains of expertise (food respectively biobased value chains). This shared vocabulary will help making assumptions explicit and making data and models accessible and usable for other researchers and stakeholders. ${ }^{10)}$ The ontology can also be used in the next step to develop the envisaged systems-approach. 


\section{WHAT ARE THE MAIN BOUNDARIES AND ASSUMPTIONS?}

Externalities and Current cost calculation methods do not take into account all the resources that allocation of external costs are used along the process of production. In the situation that the outcome of this process generates a negative effect on an environment, community or society as a whole, this is referred to as a negative externality. Pollution is an example of such a negative externality. Also the emission of greenhouse gasses, which can be attributed to the manufacturing of a product and to the processes needed to deliver, use and dispose the product, is a negative externality. Negative externalities and the quantification and allocation of the costs of these externalities (external costs) have become increasingly relevant in the debate on how to reduce the environmental impact of agricultural and food production. The need to maximise resource use efficiency (land, water, energy, additional nutrients) requires the recalculation of all costs, including any hidden external costs to a product or service, thus reflecting the real value or true price of it. This true price may change in the course of time due the fact that new insights give reason to revalue the externalities and the intrinsic quality of biomass, and so increasing its value.

Efficiency and effectiveness of input and output
Multiple ingredients and functionalities
It is important to develop options to increase the efficiency and effectiveness of resources used in biomass value chains. Possible options are:

1. Minimise the input from constraining resources by applying alternative resources:

o substitute fossil energy with renewable energy;

0 minimize energy use, e.g. by drying less and by accepting a lower purity of intermediate products.

2. Maximise output from constraining resources:

o use crops more effectively, e.g. by improving the efficiency of processes, utilizing process and product residues as alternatives for the primary feedstocks that originate from crops (upgrade residues), or by recycling;

o reduce product losses and waste, e.g. by organising the value chain (responsiveness, shorter lead times, reduce losses) and by improving product durability;

o cascading of product uses, e.g. value added cycle use of secondary and tertiary biomass feedstock.. ${ }^{11}$

The premise for taking these actions is that biomass can be exploited better by optimising the many waste streams. ${ }^{12}$ Another premise is that the integration of food and biobased value chains will facilitate the 'extraction' of multiple ingredients and functionalities from a biomass feedstock. The integration of 
value chains will avoid end-of-pipe waste streams by closing supply chain loops. The cross-overs between value chains from different sectors will result in the optimal use and valorisation of resources as a result of the exploitation of these functionalities.

Adaptiveness Individual value chains will have to be able to operate with a certain flexibility to adapt their value chain given (the fluctuations in) the availability and quality of biomass feedstock (input), and the demand for biobased product (output). The adaptiveness of a value chain, in other words, refers to the ability to handle the dynamics of the system with regards to the quantity and quality of feedstock, and to do this in coherence with other value chains. 


\section{VISION STATEMENT: INTEGRATED ADAPTIVE VALUE CHAIN NETWORKS NEEDED IN THE BIO-ECONOMY}

From single linear value chains...

... to an

integrated

network of adaptive value chains ...

\footnotetext{
... needing integration and cross-overs within ...
}

What we currently see is that various approaches to improve resource use efficiency in linear value chains typically only focus on one or more links within this particular value chain. Feedstocks in these value chains are mostly dedicated to a specific final product and markets. From a whole system perspective this single value chain approach can lead to a suboptimal situation due to the fact that the production process of the primary product (often food) in the value chain is leading. The quality of the residues is then considered less relevant and to be entirely dependent on the requirements of the production process of the primary product. To really be able to cope with the future challenges, the integration of different value chains is needed, for example from the agricultural and the chemical sector. The cross-overs between value chains from different sectors will generate a higher overall resource use efficiency in the whole system that will exceed the resource use efficiency of the individual chains. So the role of synergy is very important. Integration of food, feed and biobased value chains into adaptive value chain networks is considered, in this vision, as a key-concept that is essential to achieve overall resource efficiency and effectiveness in the whole system.

In this approach the circularity of value chains is a means to achieve coherence and synergy between value chains within these networks. Circularity of biomass feedstocks and the exchange of these feedstocks between chains, will optimise the conversion of bioresources into marketable and consumable products. This approach also refers to the establishing networks of value chains that until now have been separated by distance or sectorial borders. Integration within these value chain networks of activities for the processing of biomass materials will be driven by supply and demand dynamics. The outcome of such an integration will reflect an ecological and financial optimum for the entire network. Integration also brings along new business opportunities (clean tech) and risks that have been unknown so far. ${ }^{13)}$

So the main challenge is to design integrated value chain networks as optimised systems in which the respective demand for feedstock for food, feed and biobased products is matched simultaneously and well-tuned. These value chain networks can be based on primary biomass feedstocks, but also on residues from various production processes (secondary feedstocks), as well as on residues from households after consumption (tertiary feedstocks). In the chain of processes intermediate products are being formed, to be used for further processing in relation to the market. The challenge for each actor in the value 
chain is to look beyond the boundaries of his own biomass value chain, as well as outside the sector in which he operates, in order to avoid lock-ins.

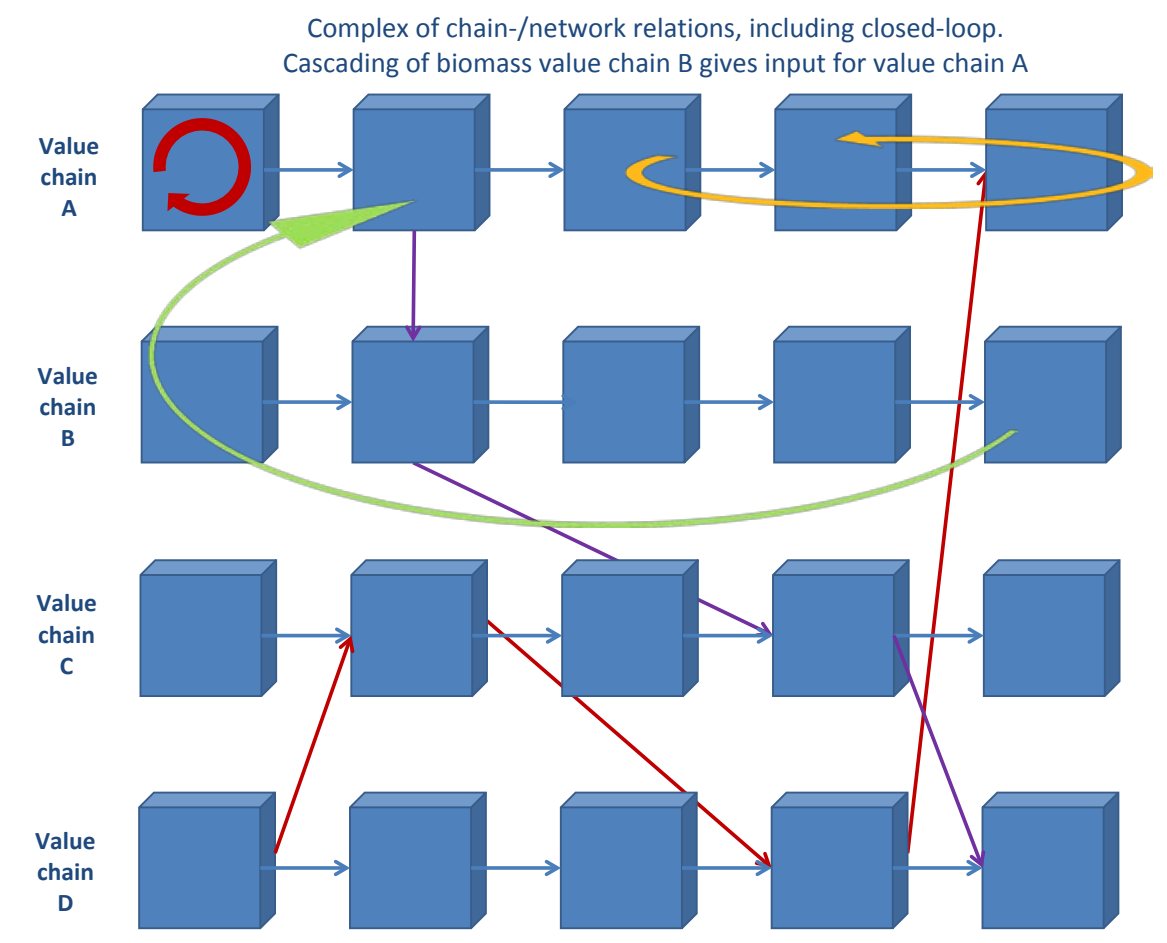

Graph 5. Integration within and cross-overs between value chains

... circular value chain networks and ...
In the new situation value chains will shift from linear chains with one main product and several residues to circular value chain networks with multiple valuable (intermediate) products and no residues. In order to achieve this new situation it will be necessary to establish the optimum of the entire network of integrated value chains from different sectors (food, feed and biobased). This means that sometimes initial concessions have to be made by the individual value chains and actors (e.g. concerning quality and allocation of costs), in order to achieve a better overall result within the whole network. The consequence would be that a certain value chain accepts a slightly lower quality (but still sufficiently within specifications) of their main product. This would then give the opportunity to produce additional intermediate products, that could be brought to more additional value as feedstock in another value chain.

The sustainability revenues of such an integrated value chain network are twofold. The circularity of primary, secondary and tertiary biomass feedstock is facilitated by the network, and therefore the resource use efficiency will increase. Secondly, the biobased products in the network will replace the more environmentally costly fossil based products. Apart from standard operational logistical optimizing tools, new models will be necessary to oversee the economic and environmental impact of transactions within the complete value chain network and to be able to judge effects on the efficiency and 
...a level playing field with adequate legislation and data transparency, leading towards ...
... a systems approach effectiveness of the resources used in the production processes. Also network directed planning will be necessary instead of single value chain planning. Finally, progressing technological development and innovation will make it possible to unravel, convert and stabilise biomass feedstock for further processing into components, and so to establish value chain networks.

In the next 10-15 years the basis for the integration of production and processing has to be created. Food and waste legislation should determine the playing field for circular food and biobased value chains. Within the boundaries of food safety and health regulations the exchange, use and re-use of biomass feedstocks should be facilitated. The added value will not only be determined by an economic driver, but also by environmental issues with a societal impact. So the added value of the whole agro-network, including the environmental impact, has to be overseen. This makes it necessary to create transparency about the data in the individual value chains. An example could be an overview of flows which are currently in low value use. The government therefore needs to create a level playing field in which transparency within and between value chain networks creates the possibility for integration of biomass flows into different processing systems, taking into account the hygiene and safety regulations for food and pharma.

The systems-approach that we envisage for a sustainable bio-economy will lead to the organisation of value chain networks in such a way that resources are used to their full potential for the purpose of food and biobased production. All product residue streams are processed and valorised to their cascading potential within a network of interconnected value chains and within the system constraints for safe production and consumption. Crucial parts of this systems-approach are, therefore, (1) taking resource use efficiency and effectiveness as a basis, (2) establishing integrated value chain networks in the bio-economy, (3) building an integrated assessment framework and (4) coping with challenges in processing, logistics, legislation and business economics. 


\section{WHAT ARE THE MAIN CHALLENGES?}

Processing

Legislation

Logistics
A big challenge is to develop new biorefinery processes with a minimum impact on the environment and with a high resource use efficiency. Because many components in the heterogeneous biomass raw materials need to be valorised, more separation processes have to be developed to extract these valuable components. An example is the change from water-based separation technologies to dry separation methods. Also new methods for conversion to increase the employability of biomass as feedstock for biorefinery, as well as techniques for stabilising and preservation of biomass, have a determining role in the realisation of decoupling points in the value chain and the development of successful networks.

An additional challenge is formed by legislation specifying the different hygienic requirements for food products in comparison to non-food products. If a component will be used for human consumption the processing circumstances will be more complicated and subjected to strict regulations. It will therefore be important to take into account the quality of the intermediate products with respect to its purity and its food grade-ness. Microbiological safety standards stipulate that a food product can only be graded to a lower level of microbiological safety. As a rule it cannot be rerouted to a higher level even though such an upgrading is technically possible through biorefinery processing and is done within the microbiological safety restrictions. Where biorefinery would enable such an upgrading the regulatory framework should allow for science-based deviations. Also the distinction between food and pharma will become less absolute (nutraceuticals) in the future, needing new regulations for the qualities demanded. The same line of reasoning holds for certain bio-materials that are declared as waste by law, giving restrictions for further use, but that can be fermented and/or refined to bio-component, biopolymers, 'green' chemicals, etcetera.

The integration and linking of food and non-food value chains in value chain networks will pose logistical challenges. One of these logistical challenges is how to organise the fluctuating supply of biomass feedstocks (volume and quality).

The organization of supply and demand of bioresources is essential for the bioeconomic developments ${ }^{14}$ ). Tradable qualified biocommodities (biobased intermediates of a standardized quality) are needed. Furthermore new markets need to be created for both niche and bulk biobased products.

Maintaining the quality of biomass feedstock is important in order to meet the 
required specifications for biorefinery. In other words, the challenge how to organise the required feedstock in the right time and place, with the right quality and specifications. This includes, amongst others, how and where to buffer these feedstocks, which pre-treatment processes are necessary to preserve its quality or to increase bulk density of biomass in the value chain. ${ }^{15}$ In short, the organisation of all activities that will enable the widening of the processing time-window and the decrease of logistical costs.

The availability and sharing of sufficient data by the different companies in a value chain or value chain network is also an important precondition for the evaluation of the efficiency of the resource used. ${ }^{16)}$

On the short term the transition to a bio-economy may slow down economic economics growth because the transition phase requires large investments. The technical, social and institutional transformation and the start-up nature of capacities may initially create uncertainties and hence higher costs. 


\section{AnNex A - Definitions}

Bio-economy

Biobased economy

Biobased materials

Biobased products

Bio-cascading

Biomass

Bioresources

Circular economy
The bio-economy comprises those parts of the economy that use renewable biological resources from land and sea - such as crops, forests, fish, animals and micro-organisms - to produce food, materials and energy. The bio-economy encompasses the production of renewable bioresources and their conversion into food, feed and bio-based products and bio-energy. The bio-economy hence provides alternatives to fossil-based products and energy, and can contribute to the circular economy. ${ }^{17), 18)}$

The biobased economy (BBE) is an economy that uses biomass for the production of materials, chemicals, transport fuels and energy (electricity and heat) ${ }^{19)}$

Materials based on biological resources (such as wood, crops or fibres) that can be used for a wide range of products (construction, furniture, paper, food, textile, chemicals, etc...) and energy uses (e.g. biofuels). Biobased materials can present advantages linked to their renewability, biodegradability or compostability. On the other hand, using biological resources requires attention to their lifecycle environmental impacts and sustainable sourcing. The multiple possibilities for their use can also generate competition for them and create pressure on land-use. ${ }^{20)}$

Bio-based products are products that are wholly or partly derived from materials of biological origin, excluding materials embedded in geological formations and/or fossilised. (CEN) ${ }^{21)}$

The concept of bio-cascading prescribes that biomass is used sequentially as often as possible as material and finally for energy. Cascading use increases resource efficiency, the sustainable use and the generation of value added from biomass and is part of the circular economy. ${ }^{22}$ )

Biogenic materials from a biological origin (crops, residues, wood, aquatic biomass). Biomass is referred to as a renewable feedstock for biorefinery. Whether biomass is renewable or not depends on the ability to use renewable and regenerative resources in the processes of production and distribution.

Bioresources are biogenic (natural organic) substances which can be used by humans for multiple purposes: to produce food and feed, to produce substantial products (pulp and paper, timber, chemicals and other bio-based products) and to produce energy carriers. ${ }^{23}$

In its 2015 action plan 'Closing the Loop' the European Commission defined the circular economy as an economy 'where the value of products, materials and resources is maintained for as long as possible, and the generation of waste minimised. Purpose of the circular economy is to develop a sustainable, low carbon, resource efficient and competitive economy'. ${ }^{24)}$ 
Closed loops

Externalities

Feedstock

Food waste

Regime

Resource use efficiency

Resource use effectiveness

System
Closed loops refer to chains in which the reusing of biological nutrients and recirculation of durable materials is enabled. Supply chains that are referred to as 'closed loop supply chains' are structured in accordance with the bio-cascading principle for valorisation of biomass. $\left.{ }^{25}\right)$

Externalities refers to situations when the effect of production or consumption of goods and services imposes costs or benefits on others which are not reflected in the prices charged for the goods and services being provided. Externalities arise when property rights cannot be clearly assigned. Negative externalities arise when an individual or firm does not bear the costs of the harm it imposes. Positive externalities arise when an individual or firm provides benefits for which it is not compensated. ${ }^{26)}$

Feedstock refers to the different types of biomass that can be used in a process for the production of food, feed, and/or products from biorefinery production (materials, chemicals, energy). Feedstock can be primary: dedicated biomass for food and high-value biobased products, or secondary: residue biomass and waste streams for high and medium value biobased products and energy, or tertiary: food - and garden waste for medium and low value biobased products, and energy.

Food waste is an increasing concern in Europe. The production, distribution and storage of food use natural resources and generate environmental impacts. Discarding food that is still edible increases these impacts, and causes financial loss for consumers and the economy. Food waste also has an important social angle: donation of food that is still edible but that for logistic or marketing reasons cannot be commercialised should be facilitated. ${ }^{27)}$

A regime is defined as a complex of engineering practices, production process technologies, product characteristics, skills and procedures, ways of handling relevant artefacts and persons, ways of defining problems - all of them embedded in institutions and infrastructures. Summarised, a regime consists of the sectors and their institutions (collection of rules and procedures), material (infra)structure and cultures. ${ }^{28)}$

Measure for the inputs transformation to the desired output. ('Doing things right').

Measuring of the inputs transformation to the creation of customer value ('Doing the right things').

A system consists of elements that are interconnected and influence each other in a certain direction. A system can be an economic sector, branch of industry, a city or a region. The system level is the overarching level on which individuals, companies and organisations have organised themselves. System innovations transcend organisations as renewals that fundamentally alter the connections between companies, organisations and individuals. ${ }^{29)}$ 
Transitions, or system innovations, are fundamental changes in the way a society has organised its basal functions (such as transport, food production, energy supply, or medical care). Transitions are always accompanied by changes in the structure of the regime (legal and financial rules, in the norms and routines that are acknowledged, who matters and who doesn't, knowledge and the existing physical infrastructure). ${ }^{30}$ 


\section{ANNEX B - RESEARCH CONTEXT OF THIS PAPER}

Brief introduction on the vision paper

\section{Strategic research: Biorefinery \& Chains R\&D programme}

This vision paper was drafted by research scientists from Wageningen UR Food \& Biobased Research (FBR). It represents the vision of this group on how to achieve, and therefore how to assess the resource efficiency and effectiveness of value chains in the bio-economy. This vision is part of research line 2 'Redesign of Efficient Food and Biobased Chains' in the strategic research programme 'Biorefinery \& Chains'.

In the 'Biorefinery \& Chains' research programme several knowledge institutes within Wageningen UR have combined their expertise to find answers to the question how to enable a transition to a more efficient and effective use of the available resources in biomass value chains. In its Strategic Plan 2015-2018 the board of Wageningen UR labelled Resource Use Efficiency as one of the five strategic themes. The aim is to invest in the development of knowledge and expertise on how to increase the efficiency of the available resources ${ }^{31}$.

The 'Biorefinery \& Chains' research programme has been defined on the basis of the multi-level perspective on societal transitions and technical innovations. The core notion of the multi-level perspective (MLP) is that transitions come about through interactions between processes at different levels: (a) niche innovations build up internal momentum, (b) changes at the landscape level create pressure on the regime, (c) destabilisation of the regime creates windows of opportunity for niche innovations.

The Biorefinery programme is defined by three research lines, that are aligned with the three levels in the multi-level layer perspective:

1. landscape level: biomass demand and supply map

2. regime level: redesign of efficient food and biobased chains

3. niche level: biorefinery technology development

This document links to research line 2 and deals with methods to increase resource use efficiency from a regime level or value chain perspective. The regime, in this case, contains the following sectors and their institutions, material (infra) structures, and cultures that are relevant in our analysis: the chemistry regime, the agri \& food regime, and the energy regime. As such, the regime is approached as a complex network of value chains that is involved in the production and processing of biomass for food and non-food purposes.

Key-words Value chain, supply chain, redesign, biomass, food, biobased, network, resilience, bio-economy, circular economy, resource use efficiency, resource use effectiveness. 


\section{ANNEX C - Notes}

1) Statement from the European Bio-economy Stakeholders Manifesto Building blocks, version: concept April $13^{\text {th }}$. This manifesto was concluded at the $4^{\text {th }}$ Bio-economy Stakeholder Conference in Utrecht, 12-13 April 2016.

2) Amongst which, Dutch Government (2016): Government-wide programme for a circular economy: a circular economy in the Netherlands by 2050; MacArthur Foundation (2015): Growth Within a Circular Economy; Vision for a Competitive Europe; European Commission (2015) - Closing the Loop; an EU Action Plan for the Circular Economy; EUBIOS Conference (2016):European Bioeconomy Stakeholders Manifesto

3) Vorst, J.G.A.J van der \& Snels (J.) (2014). Developments and needs for sustainable agro-logistics in developing countries. World Bank Position Note, World Bank Group / The Netherlands Ministry of Foreign Affairs.

4) Wilde, S. de (ed.) (2015). Van Autonome robots tot zilte aardappels. Toekomstverkenning naar de invloed van technologische ontwikkelingen op de agri- $\&$ foodsector tot 2050. Stichting der Techniek, STT-publicatie 81. Den Haag.

5) European Commission (2015). Closing the loop - An EU action plan for the Circular Economy. Communication from the Commission, Brussels, 2.12.2015 COM(2015) 614 final

6) European Commission (2015), directorate general for Research and Innovation. Sustainable Agriculture, Forestry and Fisheries in the Bio-economy: a challenge for Europe. 4th SCAR Foresight Exercise. European Union, Brussels.

7) European Commission (2015), directorate general for Research and Innovation. Sustainable Agriculture, Forestry and Fisheries in the Bio-economy: a challenge for Europe. 4th SCAR Foresight Exercise. European Union, Brussels

8) Bos-Brouwer, H., Langelaan B., Sanders J., Dijk M. van, Vuuren A. van (2012). Chances for biomass; integrated valorisation of biomass resources. Wageningen UR

9) Dam J.E.G. van, Elbersen W. \& Ree, R. van (2014). Setting up international biobased commodity trade chains. Wageningen UR Food \& Biobased Research.

10) Scholten, H. (2003). Ontologie, een manier om kennis te structureren. Kwartaalblad Agro-Informatica $16-2$, p. $7-11$

11) Primary feedstock: dedicated biomass for food and high-value biobased products; secondary feedstock: residue biomass and waste streams for high and medium value biobased products and energy; tertiary feedstock: food - and garden waste for medium and low value biobased products, and energy.

12) This is the same premise that was postulated by the Standing Committee of Agricultural Research in its $4^{\text {th }}$ SCAR Foresight Exercise in 2015 (Sustainable Agriculture, Forestry and Fisheries in the Bioeconomy - a Challenge for Europe, European Commission Directorate General Research \& Innovation, Brussels 2015)

13) Bino, R. et al. (2015). High Efficiency Use of Resources. (non-published Wageningen UR position paper)

14) Dam, J.E.G. van, et al. "Securing renewable resource supplies for changing market demands in a biobased economy." Industrial crops and products 21.1 (2005): 129-144. Elsevier.com 
15) Annevelink E., Oever M.J.A. van den, Gogh J.B. van, Dam J. van (2015). Mogelijkheden voor de implementatie van het biomassawerf concept in de Greenport Gelderland (deel3: logistieke cases). Wageningen UR Food \& Biobased Research Report 1546.

16) This aspect was also put forward by Lieder (2015) as objective for forthcoming research investigations as the "development of an information analysis service for production systems of discrete production which supports and facilitates the increase of resource efficiency and effectiveness." (p.106 Lieder M. (2014). Integrated evaluation of resource efficiency and cost effectiveness in production systems. KTH Royal Institute of Technology, Stockholm.)

17) EC (2012). Innovating for Sustainable Growth; a Bio-economy for Europe. DG for Research and Innovation, European Union, Brussels 2012

18) EC (2015). Closing the loop - An EU action plan for the Circular Economy. Communication from the Commission, Brussels, 2.12.2015 COM(2015) 614

19) http://www.rvo.nl/onderwerpen/duurzaam-ondernemen/groene-economie/biobased-economy

20) European Commission (2015a). Closing the loop - An EU action plan for the Circular Economy. Communication from the Commission, Brussels, 2.12.2015 COM(2015) 614 final

21) European Commission (2012). Innovating for Sustainable Growth; a Bioeconomy for Europe. European Union, Directorate General for Research and Innovation, Brussels 2012

22) European Commission (2015). Sustainable Agriculture, Forestry and Fisheries in the Bio-economy - a Challenge for Europe. SCAR $20154^{\text {th }}$ Foresight Exercise. European Commission, Brussels.

23) European Sustainable Energy Innovation Alliance (ESEIA) (http://www.eseia.eu/wg1/)

24) EC (2015). Closing the loop - An EU action plan for the Circular Economy. Communication from the Commission, Brussels, 2.12.2015 COM(2015) 614

25) Ellen MacArthur Foundation (2015) - Towards a circular economy: business rationale for an accelerated transition. United Kingdom.

26) OECD (1993).Glossary of Industrial Organisation Economics and Competition Law. OECD, Paris.

27) European Commission (2015). Closing the loop - An EU action plan for the Circular Economy. Communication from the Commission, Brussels, 2.12.2015 COM(2015) 614 final

28) http://www.transitiepraktijk.nl/nl/experiment/definitions

29) Rotmans, J. (2003). Transitiemanagement - sleutel voor een duurzame samenleving. Van Gorcum, Assen.

30) Rotmans, J. (2003). Transitie-management - sleutel voor een duurzame samenleving. Van Gorcum, Assen

31) Wageningen UR Strategic Plan 2015-2018 (published 2015). Other strategic research investment themes are: Global One Health, Resilience, Metropolitan Solutions, and Synthetic Biology. 